\title{
LAND COVER AND LAND USE CHARACTERIZATION WITH GEOBIA IN THE PITANGUI RIVER BASIN AREA, PARANÁ-BRAZIL.
}

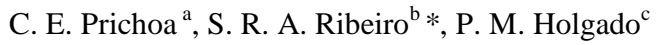 \\ ${ }^{a}$ Department of Geography, Autonomous University of Madrid, Spain, Street Francisco Tomas y Valiente 1 Ciudad Universitaria \\ Cantoblanco, 28049, Madrid - pedro.molina@uam.es; prichoa.carla@gmail.com \\ ${ }^{\mathrm{b}}$ Department of Geography, State University of Ponta Grossa, Avenida General Carlos Cavalcanti, 4748 - Paraná, 84030-900, Brazil - \\ selmar.aranha@gmail.com
}

KEY WORDS: GEOBIA, Land Cover and Land Use, Compact and Solidity.

\begin{abstract}
:
GEOBIA - Geographic Object-Based Image Analysis - is considered to be a technique that takes advantage of several Remote Sensing dimensions - like spectral, spacial, morphologic and contextual information - together with functionalities of Geographic Information Systems (GIS) as well. GEOBIA unit of analysis is an image object that obtains complete information. It includes texture, shape and spatial relations to neighboring objects and ancillary spatial data to different resolutions. In this study, it was sought to identify - in the spatial, spectral and texture descriptor group generated with GEOBIA - those that most represent the study unity. The technique was applied in part of the scene 221/77 of Landsat 5 TM satellite from year 2010 in color composition R5G4B3. This area belongs to the Pitangui river basin located at the center-east portion of the State of Paraná - Brazil, between coordinates $600.987 \mathrm{~m} \mathrm{E}$ and $7.240 .620 \mathrm{~m} \mathrm{~N}$ to $614.973 \mathrm{~m} \mathrm{E}$ and $7.231 .568 \mathrm{~m} \mathrm{~N}$ and zone $22 \mathrm{~S}$. Segmentation tests were done adjusting scale and merging levels according to the proposed objective (analysis of land use). Using a group of 35 descriptors with spatial, spectral and texture characteristics, Principal Component Analysis (PCA) and clustering were respectively applied with the aim of decreasing dimensionality of descriptors and grouping similar ones according to the shortest euclidean distance. From 14 resulting descriptors analyzed in the dendrogram generated in the clustering procedure, only compactness and solidity were grouped in the shortest euclidean distance. In the descriptors graph, maximum and minimum values for compactness and solidity have presented linear increase enabling the previous analysis.
\end{abstract}

\section{INTRODUCTION}

Remote sensing orbital images are considered to be one of the most traditional sources to acquire information about the earth's surface. This information is the basis for a great deal of practical applications including local, regional and global resource monitoring, land cover and its changes, as well as basis for other environmental studies.

The increasing ability to collect and manage high-resolution data has become a challenge to the traditional methods of image analysis, specially to the ones based on spectral characteristics. Advanced techniques such as GEOBIA - Geographic ObjectBased Image Analysis - are alternatives to the traditional pixelbased paradigm, specially when dealing with the data originating from high-resolution images. Thus, besides spectral properties, objects have numerous descriptors associated with shape, texture, contextual and semantic relationships which can be used for image analysis; it approaches this way human cognitive processes of photo interpretation (Navulur, 2006; Marpu, 2009; Camargo et al, 2009a) and therefore it can be applied to environmental studies for various purposes, and it serves as basis for land management.

The unit of analysis GEOBIA is an image-object that obtains complete information. It includes texture, shape and spatial relations with neighboring objects and ancillary spatial data for different spatial resolutions (Gutiérrez-Aguirre et al, 2012; Bock et al, 2005). This allows for an exploration of spatial context which is similar to a human analyst, who intuitively identifies objects in an image rather than individual pixels. It considers different properties (size, texture, shape) and spatial arrangements of these objects in order to understand its semantics (Addink et al, 2012. Marceau, 1999).

Compared to pixel-based approaches, GEOBIA facilitates multiscale analysis allowing to outline the landscape at different levels, reducing small spurious changes and provides a significant increase in the number of features that can be examined in a given analysis (HayandCastilla, 2008).

Previous studies have shown that improved results and higher accuracy in image classification is achieved when GEOBIA is applied (Desclée et al, 2006; Im et al, 2008b; Johansen et al, 2010; Lingcao et al, 2010; McDermid et al, 2008; Robertson and King, 2011; Zhou et al, 2008a).

The image is divided into sub-objects where scale and merging may be adjusted according to a proposed objective. The choice of the scale parameter and the similarity criteria are related to the spatial and spectral resolutions of the image. The term object is characterized as the main element in this type of analysis. This demonstrates that the necessary semantic information to interpret an image is not inserted into the pixel, but in the object produced in the image and the relationships between them (Definiens 2008). This fact increases the amount of features used for identifying different targets from the image;

\footnotetext{
* Corresponding author
} 
it is possible, however, to reduce dimensionality through statistical techniques like Principal Component Analysis (PCA). PCA is an alternative to describe heterogeneous areas such as the one in this study.

Based on these assumptions, the objective of this study is to use the GEOBIA technique in part of the scene 221/77, colorful makeup R5G4B3 from Landsat $5 \mathrm{TM}$, to identify those descriptors among the set of spatial, spectral and textural descriptors resulting from segmentation, that better represent its physical aspects, land cover and land use in 2010.

\section{STUDY AREA AND METHODOLOGY}

The study area (Figure 1) is part of the Devonian Escarpment ${ }^{1}$ in the Pitangui river basin located in the central eastern part of the State of Paraná - Brazil, between coordinates: $600.987 \mathrm{~m} \mathrm{E}$ and $7.240 .620 \mathrm{~m} \mathrm{~N}$ to $614.973 \mathrm{~m} \mathrm{E}$ and $7.231 .568 \mathrm{~m} \mathrm{~N}$ and zone $22 \mathrm{~S}$.

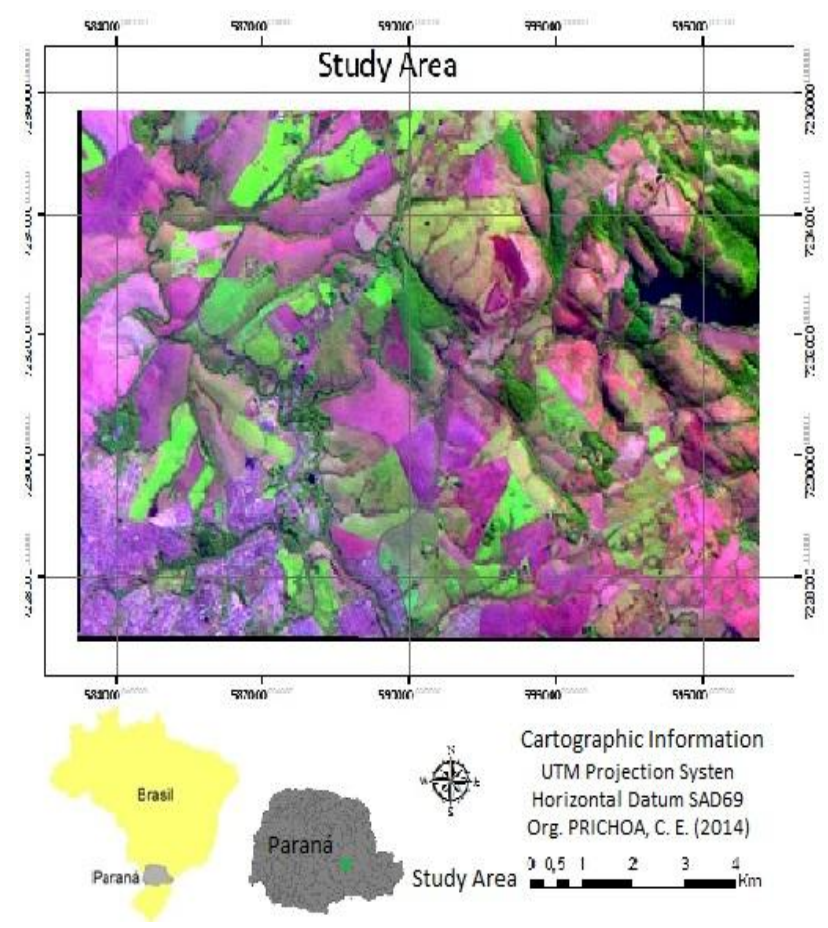

Figure 1. Location of the study area

In the performed segmentation tests, pixels were grouped according to the proposed objective: to analyze the use, utilizing Merge Level 91.7 and Scale Level 45.6. Departing from the set of 35 descriptors with spatial, spectral and textural features obtained through GEOBIA; Principal Component Analysis (PCA) and Cluster Analysis (CA) were applied in order to, respectively, reduce the dimensionality of the descriptors and group similar ones in shorter Euclidean distance. This resulted in 14 descriptors and two of them, Compact and Solidity that were analyzed in the dendrogram generated by CA, grouped themselves in the shortest Euclidean distance. Thus, compact and solidity are descriptors that have

${ }^{1}$ The origin of the name is due to the rock that supports it (Furnas Formation) from Devonian age (about 400 million years). best represented the study area and the ones through which the description of physical features of land cover and use can be conducted.

The calculation of PCA consists in a matrix whose rows are the eigenvectors of the covariance matrix estimated from data. The covariance matrix $\Sigma$ is a positive and symmetric matrix that contains information about the variances in all axes where data is distributed. The calculation is estimated as follows:

$$
S=\frac{1}{n} \sum_{i=1}^{n}\left(x_{1}-\bar{x}\right)\left(x_{1}-\bar{x}\right)^{n}
$$

Where: $\mathrm{n}$ is the number of data samples, $\mathrm{xl}$ is the mean of the set.

CA consists in grouping the closest pairs of variables, using the Euclidean distance for such and then replacing them with a new variable located at the half-distance between them. Euclidean distance (xjh) refers to the distance between two variables $\mathrm{j} e \mathrm{~h}$ in n-dimensional space and is given by:

$$
x_{j h}^{2}=\sum_{i=1}^{n}\left(x_{I j}-x_{i n}\right)^{2}
$$

\section{RESULTS AND DISCUSSION}

The study area presents heterogeneous characteristics as to the physical aspects and to land cover and use. It is predominantly an agricultural area, formed by valleys of the Pitangui river and tributaries, and an urban portion in the southwest as well. The descriptors compact and solidity (Figures 2 and 3) were those which displayed greater representativeness in the ACP and $\mathrm{CA}$ and thus best characterize the area.

The compact descriptor can vary from 0 to 1 . Nevertheless, in Figure 2, compact shapes are distributed within limits ranging from 0.072 (lower compactness, less rounded) to 0.294 (greater compactness, the more rounded shapes). Although values of compactness of the area are low, the descriptor provides pertinent representativeness attributes of land cover and use. Once that presenting the shortest Euclidean distance it hence represents forms originated by land use, mainly agriculture which are characterized in their great majority by plots displayed as solid and rectangular of various perimeters, just as highlighted in the image (circles, orange and green plots). 


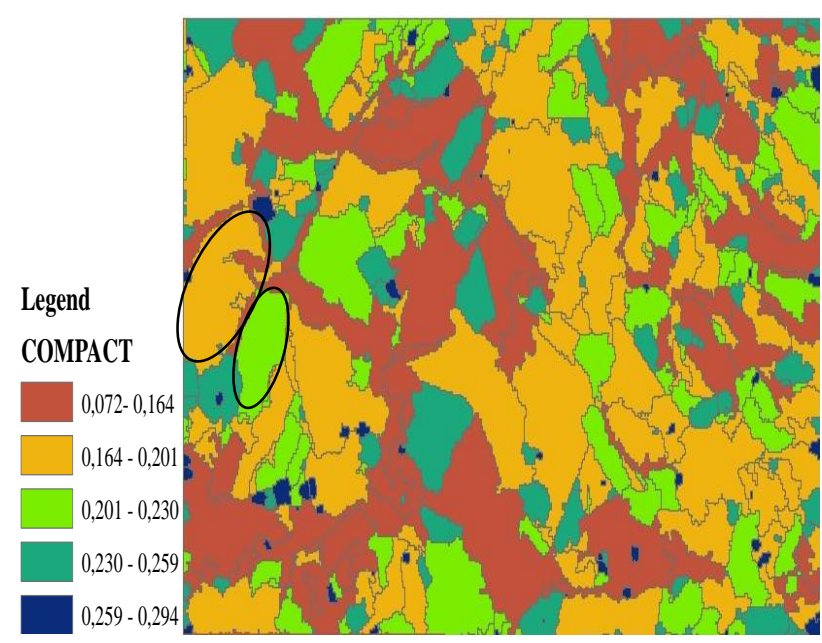

Figure 2: Compact Descriptor

Solidity varies from 0 to 1 and also offers high representativeness to the study area according to PCA and CA. In Figure 3, minimum and maximum values of descriptor are respectively distributed between 0.370 and 1 . The most solid objects refer to those of lower compactness (circles); they represent delimited agricultural areas of various geometry and for the most part rectangles without divisions or spurious elements. Intermediate values of solidity and low compactness in most of the area are associated with large scale agricultural land use, considering that this region has appropriate geomorphological conditions for such: from mild relief to wavy with flat tops and fertile soils.

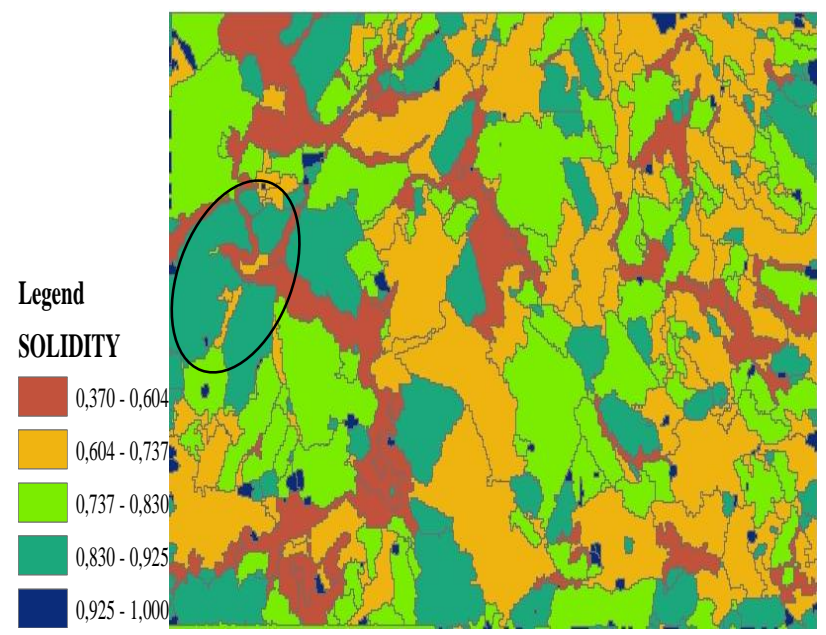

Figure 3: Descriptor Solidity

Each descriptor resulting from the GEOBIA technique possesses numerical properties that represent real-world features. In the graph (Figure 4) characteristics of descriptors compact and solidity are represented by the variation of the maximum and minimum values in each point. The graph shows that the values of descriptors compact and solidity increase coming close to a straight line, i.e. they display a linear relationship.
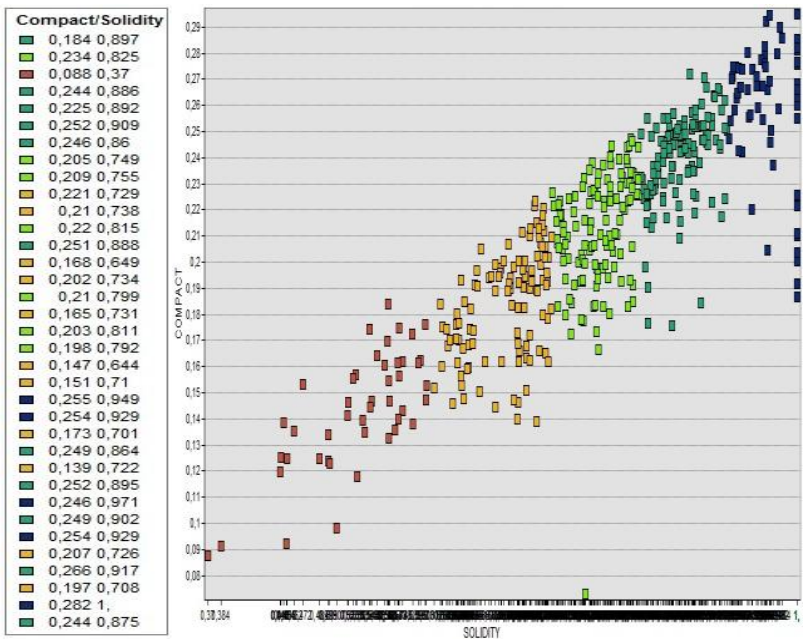

Figure 4: Maximum and minimum values of descriptors compact and solidity.

\section{CONCLUSIONS}

Land cover and land use can be identified and characterized by means of descriptors (compact and solidity) arising out of the GEOBIA technique when applied to an area that presents heterogeneous uses. The GEOBIA technique enabled the extraction of information from spatial context, incorporating to the spectral information characteristics of shape, size and texture of objects as well as other spatial phenomena of interest. GEOBIA applied in combination with the analysis of data dimension reduction and clustering made possible both the identification of homogeneous objects and their association with the study area. The descriptors compact and solidity presented the highest correlation when PCA and CA tests were performed, as well as the distribution of pairs in the graph (Figure 4) that are linearly positioned to one another.

The result proved to be suitable for this type of study, which emphasizes geometric shapes of objects of intermediate solidity and low compactness, associating them to land use and then to polygons with large perimeters. It is hereafter suggested to apply this method in monoculture areas in order to relate them to the type of cultivation.

\section{REFERENCES}

Addink, E. A., Van Coillie, F. M. B., De Jong, S. M., 2012. Introduction to the GEOBIA 2010 special issue: from pixels to geographic objects in remote sensing image analysis. International Journal of Applied Earth Observation and Geoinformation 15, 1-6.

Aguirre-Gutiérrez, J., Seijmonsbergen, A. C., Duivenvoorden, J. F., 2012. Optimizing land cover classification accuracy for change detection, a combined pixel-based and object-based approach in a mountainous area in Mexico. Applied Geography 34, 29-37. 
Bock,M., Xofis, P., Mitchley, J., Rossner, G., Wissen, M., 2005. Object-oriented methods for habitat mapping at multiple scales - case studies from Northern Germany and Wye Downs, UK. Journal for Nature Conservation $13,75-89$.

Definiens. Ecognition: user guide 3. Germany. http://www.definiens-imaging.com/down/ecognition.

Report.html (January 2014).

Desclée, B., Bogaert, P., Defourny, P., 2006.Forestchange detection by statistical object-based method. Remote Sensing of Environment 102, 1-11.

Hay, G. J. and Castilla, G., 2008. Geographic ObjectBased Image Analysis (GEOBIA). In: Blaschke, T., Lang, S., Hay, G. J. (eds) Object-Based Image Analysis Spatial concepts for knowledge-driven remote sensing applications. Chapter 1.4, pp. 81- 92 Springer. 700 p.

Im, J., Jensen, J.R., Tullis, J.A., 2008b. Object-based change detection using correlation image analysis and image segmentation. International Journal of Remote Sensing 29, 399-423.

Johansen, K., Arroyo, L.A., Phinn, S., Witte, C., 2010.Comparison of geo-object based and pixel-based change detection of riparian environments using high spatial resolution multi-spectral imagery. Photogrammetric Engineering \& Remote Sensing 76, 123-136.

Lingcao, H., Guo, Z., Yang, L., 2010. An object-based change detection approach by integrating intensity and texture differences.In: 2010 2nd International Asia 104 M. Hussain et al. / ISPRS Journal of Photogrammetry and Remote Sensing 80 (2013) 91- 106 Conference on Informatics in Control, Automation and Robotics (CAR), pp. 258-261.

Marceau, D.J., 1999. The scale issue in social and natural sciences. Canadian Journal of Remote Sensing 25, $347-$ 356.

MARPU, P. R. Geographic Object-based Image Analysis. Freiberg, 2009. 121f. Thesis (Doctorate in Engineering) Faculty of Geosciences, Geo-Engineering and Mining Technische Universität Bergakademie Freiberg, 2009.

McDermid, G.J., Linke, J. Pape, A. D., Laskin, D. N., McLane, A. J., Franklin, S.E.,2008. Object-based approaches to change analysis and thematic map update: challenges and limitations. Canadian Journal of Remote Sensing 34, 462-466.

Navulur, K. Multispectral image analysis using the object-oriented paradigm. Boca Raton: Taylor \& Francis Group, 2006. 165p.
Robertson, L.D., King, D.J., 2011. Comparison of pixeland object-based classification in land cover change mapping. International Journal of Remote Sensing 32, 1505-1529.

Zhou, W., Troy, A., Grove, M., 2008a. A Comparison of Object-Based with Pixel-Based Land Cover Change Detection in the Baltimore Metropolitan Area using Multitemporal High Resolution Remote Sensing Data, Geoscience and Remote Sensing Symposium, 2008. IGARSS 2008. IEEE International, pp.IV-683-IV-686. 